Instructions for authors, subscriptions and further details:

http://ijep.hipatiapress.com

\title{
The Disordered Mind: What Unusual Brains Tell Us About Ourselves
}

Esther Roca Campos ${ }^{1}$

1) Universidad Internacional de Valencia, Spain.

Date of publication: June $24^{\text {th }}, 2019$

Edition period: June 2019 - October 2019

To cite this article: Roca Campos, E. (2019). [Book Review of The Disordered Mind: What Unusual Brains Tell Us About Ourselves by E. Kandel] International Journal of Educational Psychology, 8(2), 214-215. doi: 10.17583/ijep.2019.4370

To link this article: http://dx.doi.org/10.17583/ijep.2019.4370

\section{PLEASE SCROLL DOWN FOR ARTICLE}

The terms and conditions of use are related to the Open Journal System and to Creative Commons Attribution License (CC-BY). 
IJEP - International Journal of Educational Psychology, Vol. 8 No. 2 June 2019 pp. 214-215

\section{Review}

Kandel, E.R. (2018). The Disordered Mind: What Unusual Brains Tell Us About Ourselves. New York: Farrar, Straus and Giroux.

Eric R. Kandel is professor in Columbia University Medical Center, and Director of the Kavli Institute for Brain Science. He is Senior Investigator at the Howard Hughes Medical Institute. Specialist in neuroscience and neurophysiology, his scientific contributions are mainly linked to the purpose of understanding the nature of the human mind through the study of learning and memory processes. His research was recognized with the Nobel Prize in Physiology or Medicine in 2000.

His most recent book, The Disordered Mind: What Unusual Brains Tell Us About Ourselves, aims to unveil the main contributions that are currently known about how to study the neurological and psychiatric brain disorders that cause some of the most incidental illnesses nowadays. As Kandel argues, such disorders provide essential information about the nature of the human mind.

Since diseases such as autism, depression, schizophrenia, Alzheimer, Parkinson, addictions or post-traumatic stress disorder modify the neural connections, they could not be formed well or even at all, this makes them be a good study aim to better understand the normal functioning of the brain. Paradoxically, Kandel explains the relevance of a neurological and social analysis of these disorders to learn more about the neural circuits that take part daily in social interactions, thoughts, feelings, behaviour, memory and creativity of people. Under this premise, Kandel analyzes each of the aforementioned disorders and the information that they reveal about the good functioning of the brain, about us.

This work deepens, for example, the genetic advances that currently exist on the Autism Spectrum and how to better understand the genes and neuronal procedure that explain the human social nature, as well as, what kind of interaction exists between the genetic predisposition and environmental factors at the origin of specific disorders. In this line, the 
study of other psychiatric conditions such as depression, bipolar disorder, schizophrenia and dementia is establishing the first connections between genetics, brain physiology and behaviour. This analysis will bring significant advances in the sense of identity of people and in the inhibition and activation of neural circuits that influence, for example, our creativity. On the other hand, Kandel also proposes an analysis of the biological influence in addictions, or also in the recognition of gender identities, to better understand and meet the needs and experiences of people with that difference.

Kandel's latest contribution in the book refers to one of the greatest scientific challenges of the 21st century: the contributions on how human consciousness is born. Emerging advances are introduced on how brain disorders not only cause alterations in aspects of conscious experience (cognition, memory, etc.) but also in the interaction of unconscious processes (information can enter the brain without producing conscious perception); they also can influence conscious decisions (that information could affect behavior).

Kandel shows in this book that there will be greater convergence between neurological and psychiatric diseases, which will continue to demonstrate the interaction between genes and the social environments that make up the brain. In this sense, a challenge present in the book is its contribution to a 'new humanism', a humanism that combines the sciences that deal with the natural world, with the humanities that deal with the meaning of human experience. Kandel exposes a biological basis of the disorders, but also, how from social and educational contexts, we can create environments that, independently from the neural involvement of each person, can be manifested to a greater or lesser extent and affect a greater or lesser opportunity of recovery. E. Kandel reaffirms in this publication the incidence of learning to produce anatomical changes in the connections between neurons. Under this evidence, a more intense interdisciplinarity is surely required in future research on the human mind.

Esther Roca Campos Universidad Internacional de Valencia esther.roca@campusviu.es 